\title{
APURAÇÃO DE HAVERES E AS DIFICULDADES DO PERITO CONTADOR
}

\author{
Sandro dos Santos Silva. Fundação Escola de Comércio Álvares Penteado (FECAP) \\ sandrosilva@edu.fecap.br \\ Natália Fontenele Tibério. Fundação Escola de Comérco Álvares Penteado (FECAP) \\ nfontenele@outlook.com \\ José Orcélio do Nascimento. Fundação Escola de Comércio Álvares Penteado (FECAP) e Universidade \\ Municipal de São Caetano do Sul (USCS) \\ jorcelio@uol.com.br \\ Marcus Vincius Moreira Zittei. Centro Universitário das Faculdades Metropolitanas Unidas (FMU) e \\ Universidade Federal de São Paulo (UNIFESP) \\ marcuszittei@zitteil.com.br
}

\section{RESUMO}

A discussão judicial entre sócios sobre a avaliação patrimonial de suas empresas faz surgir a necessidade de um profissional contábil que seja capacitado em fornecer subsídios ao juízo para a justa solução do litígio. Porém no desenvolvimento do seu trabalho, o perito contador pode se deparar com circunstâncias que dificultam o seu trabalho, seguindo nesta linha o presente estudo tem como objetivo identificar quais são as principais dificuldades encontradas pelo perito contador na apuração de haveres em processos judiciais. Por meio de um questionário estruturado com 13 questões enviados para 45 peritos contadores com atuação na cidade de São Paulo em apurações de haveres no âmbito do Poder Judiciário, no período de 06/11/2019 a $11 / 11 / 2019$, o estudo evidenciou que as principais dificuldades do perito contador na apuração de haveres em processos judiciais são: valoração do estoque, intangível e goodwill, bem como valorar todos os elementos patrimoniais quando presentes circunstâncias que dificultam o desenvolvimento do seu trabalho. Sendo tais circunstâncias: falta de escrituração contábil ou deficitária, ausência de documentos que dão suporte aos fatos contábeis, inexistência do balanço especial à época da resolução societária e a omissão de dados e/ou informações pelas partes envolvidas no litígio. Dessa forma, os resultados desse estudo demonstraram as dificuldades e captou a percepção dos profissionais que atuam na área fomentando a discussão dos pontos críticos atuais, que poderam auxíliar na busca por alternativas de modo a contribuir aos profissionais da área meios para suprir esses obstáculos.

Palavras-chave: Perícia Contábil; Apuração de Haveres; Perito Contador; Dificuldades.

Data de recebimento: $27 / 02 / 2021$

Data do aceite de publicação: 06/08/2021

Data da publicação: 30/08/2021 


\title{
INVESTIGATION OF ASSETS AND THE DIFFICULTIES OF THE EXPERT ACCOUNTANT
}

\author{
Sandro dos Santos Silva. Fundação Escola de Comércio Álvares Penteado (FECAP) \\ sandrosilva@edu.fecap.br \\ Natália Fontenele Tibério. Fundação Escola de Comérco Álvares Penteado (FECAP) \\ nfontenele@outlook.com \\ José Orcélio do Nascimento. Fundação Escola de Comércio Álvares Penteado (FECAP) e Universidade \\ Municipal de São Caetano do Sul (USCS) \\ jorcelio@uol.com.br \\ Marcus Vincius Moreira Zittei. Centro Universitário das Faculdades Metropolitanas Unidas (FMU) e \\ Universidade Federal de São Paulo (UNIFESP) \\ marcuszittei@zitteil.com.br
}

\begin{abstract}
The judicial discussion among partners about the equity valuation of their companies arises the need for an accounting professional who can provide subsidies to the court for the just solution of the dispute. However, in the development of his work, the expert accountant may face circumstances that hinder his work, following this line the present study aims to identify what are the main difficulties encountered by the expert accountant in the investigation of possessions in judicial proceedings. Through a structured questionnaire with 13 questions sent to 45 accountants working in the city of São Paulo in investigations of assets within the judiciary, in the period from $06 / 11 / 2019$ to $11 / 11 / 2019$, the study showed that the main difficulties of the accountant expert in the calculation of assets in judicial proceedings are: stock valuation, intangible and goodwill, as well as valuing all property elements when present circumstances that hinder the development of their work. Being such circumstances: lack of bookkeeping or deficit, absence of documents that support the accounting facts, lack of special balance sheet at the time of corporate resolution and omission of data and/or information by the parties involved in the dispute. Thus, the results of this study demonstrated the difficulties and captured the perception of professionals working in the area promoting the discussion of current critical points, which could help in the search for alternatives in order to contribute to professionals in the area means to overcome these obstacles.
\end{abstract}

Keywords: Accounting Expertise; Investigation of Assets; Expert Accountant; Difficulties.

\section{INTRODUÇÃO}

A valoração de uma entidade jurídica é uma prática comum no mundo empresarial que por muitas vezes ganha a atenção das mídias quando se trata de grandes corporações que geram impactos relevantes na sociedade. No ano de 2019, por exemplo, observou-se duas das maiores fusões empresariais do Brasil, uma no setor de comunicações marcada pela compra da Nextel pela Claro a outra no segmento dos cosméticos sendo a aquisição da Avon por parte da Natura. Pela dimensão econômica dessas fusões, certamente, foi necessária a realização de uma avaliação dessas empresas para chegar ao valor do negócio, a fim de consolidar seus acordos.

Nesse sentido Martins (2001) descreve que alguns dos motivos para avaliar uma empresa são: cisão, fusão, incorporação, dissolução societária, liquidação ou até mesmo para avaliar a capacidade dos administradores.

A valoração de um negócio está muito ligada a continuidade, ou descontinuidade, do negócio. No cenário de continuidade da atividade empresarial, um determinado método de 


\section{APURAÇÃO DE HAVERES E AS DIFICULDADES DO PERITO CONTADOR}

avaliação pode ser usado, enquanto na descontinuidade uma outra metodologia de valoração pode ser adotada (Paulo, Cunha, Alencar, \& Martins, 2006).

Sob o comando do poder judiciário, a valoração de uma empresa é apresentada como apuração de haveres - procedimento cujo objetivo principal é mensurar a participação societária de cada sócio. Segundo Ornelas (2003) a apuração de haveres é um procedimento judicial ordenado pelo juízo, desenvolvido por perito contador, com o objetivo de avaliar as cotas societárias.

Paulo, Cunha, Alencar e Martins (2006) explicam que o processo de mensuração é heterogêneo visto que na resolução societária quem se retira da empresa tende a maximizar o valor da mesma, do contrário, quem permanece que procura minimizar. Com esse impasse o magistrado necessita de um profissional com conhecimento técnico para valorar a participação societária de cada sócio, e, neste momento, surge o perito contador para fornecer subsídios para a justa solução do litígio.

Todavia, no decorrer da discussão da parcela societária que cabe a cada uma das partes interessadas o litígio fica exposto a sofrer interferência de diversos fatores, como por exemplo, inexistência de registros contábeis da empresa objeto da resolução. Em razão disso não é tarefa fácil avaliar uma empresa sob a tutela do poder judiciário, e embora seja um ambiente complexo e com inúmeros obstáculos, o perito contador detém o encargo ao qual foi incumbido e trazer para o juízo elementos precisos que não causem prejuízos para nenhuma das partes.

Dessa forma, tendo como ponto de discussão a apuração de haveres sob o comando do poder judiciário, se estabelece a seguinte questão que norteia esta pesquisa: quais são as principais dificuldades do perito contador na apuração de haveres em uma dissolução parcial de sociedade no âmbito do poder judiciário?

O estudo tem por objetivo evidenciar os principais obstáculos do perito contador durante o desenvolvimento do seu trabalho na apuração de haveres em dissolução parcial de sociedade dirigida pelo poder judiciário na cidade de São Paulo.

E se justifica pelo baixo número de pesquisas acadêmicas sobre o tema, bem como por se propor a ampliar a percepção dos profissionais da área identificando os pontos críticos que peritos contadores identificam na hora de realizar uma apuração de haveres, isso permite que os auxiliares da justiça tenham uma visão daquilo que pode ocorrer durante uma avaliação patrimonial comandada pelo poder judiciário, possibilitando que os responsáveis busquem alternativas antecipadamente visando a celeridade processual.

\section{REFERENCIAL TEÓRICO}

\subsection{Apuração de Haveres}

A apuração de haveres consiste em um procedimento que tem por objetivo a valoração do patrimônio de uma sociedade (ativo e passivo) e consequentemente o valor que cabe a cada sócio. Fonseca (2012) define apuração de haveres como, basicamente, o levantamento do valor correspondente à participação societária detida pelo sócio que se afasta ou é afastado da sociedade.

$\mathrm{Na}$ esfera do judiciário, os procedimentos a serem observados na apuração de haveres em dissolução parcial de sociedade estão dispostos no Código Civil (CC) de 2002 (Lei n ${ }^{\circ}$ 10.406/2002) e Código de Processo Civil (CPC) de 2015 (Lei nº 13.105/2015).

O artigo 1.031 do CC de 2002, determina que se caso não estiver definido no contrato social as diretrizes para apuração de haveres, a liquidação da dissolução parcial deverá ser feita com base na situação patrimonial da sociedade, à data da resolução, verificada em balanço especialmente levantado: 
Art. 1.031. Nos casos em que a sociedade se resolver em relação a um sócio, o valor da sua quota, considerada pelo montante efetivamente realizado, liquidar-se-á, salvo disposição contratual em contrário, com base na situação patrimonial da sociedade, à data da resolução, verificada em balanço especialmente levantado (Lei 10.406/2002).

Quanto ao que dispõe o novo CPC de 2015, primeiro cabe dizer que na vigência do CPC de 1973, a dissolução parcial de sociedade não tinha um regramento próprio, e que, portanto, eram aplicadas as normas do CPC de 1939, que permaneciam em vigor por força do artigo 1.218, inciso VII do CPC de 1973.

Com o advento do novo CPC de 2015, houve inovação no instituto da dissolução parcial de sociedade. E assim como disposto no CC de 2002, em seu artigo 606 o CPC de 2015 também dispõe sobre a prevalência do contrato social, e na hipótese de omissão deste, o valor do patrimônio deverá ser apurado em balanço de determinação, tendo como referência a data da resolução, os ativos e passivos avaliados a preço de saída (mercado):

Art. 606. Em caso de omissão do contrato social, o juiz definirá, como critério de apuração de haveres, o valor patrimonial apurado em balanço de determinação, tomando-se por referência a data da resolução e avaliando-se bens e direitos do ativo, tangíveis e intangíveis, a preço de saída, além do passivo também a ser apurado de igual forma (Lei 13.105/2015).

Sob o comando do Poder Judiciário a apuração de haveres representa um conjunto de atividades passíveis de dificuldades e complexidades, uma vez que diversos fatores podem impactar na realização da avaliação, tais como:

- A maioria das avaliações são em empresas de pequeno e médio porte, as quais não dão a devida importância a sua contabilidade e muitas vezes sequer a possuem;

- Por ser um ambiente litigioso, as incertezas são inúmeras, pois a desavença entre as partes pode levá-las a omitir dados e/ou informações relevantes à avaliação visando seu próprio benefício;

- Na valoração de uma empresa utilizam-se expectativas, às vezes, parcialmente em bases subjetivas, já as decisões judiciais devem estar fundamentadas em fatos, eventos e ocorrências objetivas;

- Ausência de trabalhos acadêmicos que tratem das particularidades inerentes ao tema. (Mondandon, Siqueira, \& Ohayon, 2008).

Nesta mesma linha Paulo et al. (2006) afirmam que dentre os problemas encontrados nas avaliações patrimoniais, os peritos contadores relataram a inexistência ou baixo nível de confiabilidade da escrituração contábil e a dificuldade de estimar valores subjetivos.

São inerentes ao processo de avaliação de participações societárias situações que Ornelas (2003) classifica como desafios, dentre elas estão a ausência de balanço especial, inexistência de escrituração contábil regular, demonstrações e escrituração contábil contestadas pelo sócio retirante.

Perez e Famá (2004) explicitam que conforme jurisprudência a apuração de haveres é realizada por meio do levantamento do balanço de determinação, devendo estar amparado por inventário físico e contábil, considerando todos os ativos (tangíveis e intangíveis) e passivos. E continuam esclarecendo que qualquer alteração nos elementos patrimoniais sucessores à data da dissolução societária não causa nenhum impacto na apuração dos haveres.

Assim como a jurisprudência, com o advento do novo CPC de 2015, em seu artigo 606 ficou estabelecido que na omissão do contrato social, o critério para apuração de haveres será o balanço de determinação. 


\section{APURAÇÃO DE HAVERES E AS DIFICULDADES DO PERITO CONTADOR}

\subsection{Avaliação de Empresas}

Segundo Perez e Famá (2004) são vários os métodos para valorar uma determinada empresa, que variam conforme o objetivo da avaliação, as características do negócio e a disponibilidade e confiabilidade das informações. Damodaram (1997) diz que não existe um modelo que pode ser considerado dentre os demais como o melhor, pois a escolha do melhor método depende das características particulares que cada empresa possui.

Embora exista diversos métodos para avaliar uma empresa, neste artigo não há pretensão de descrever os mesmos, atém-se em discutir com profundidade a avaliação de empresas em processos judiciais, que, como relatado anteriormente, é denominada apuração de haveres.

A valoração de uma empresa no âmbito do poder judiciário, fica demonstrada no balanço de determinação. A competência para elaborar tal demonstração é do perito contador nomeado pelo juízo, partindo dos próprios registros contábeis da empresa objeto da avaliação. Esse balanço não gera impacto na contabilidade da empresa avaliada e visa exclusivamente a parte que cabe ao sócio que está saindo ou aos sucessores do sócio falecido.

\subsection{Balanço de Determinação}

O balanço de determinação trata-se de um balanço patrimonial especial, que foi preparado por perito contábil, para fins unicamente judiciais, e que teve como ponto de partida o balanço patrimonial da entidade. Tal balanço, apesar de estar sendo avaliado, não provoca nenhuma alteração na contabilidade da entidade objeto da avaliação, visto que o seu objetivo é determinar os haveres do sócio dissidente, excluído ou falecido (Perez e Famá, 2004).

Ornelas (2003, p. 83), afirma que o balanço de determinação é "elaborado para a data do evento, na qual os elementos patrimoniais são avaliados e consignados a valores de mercado".

Embora o balanço de determinação não seja considerado como um método de avaliação de empresa propriamente dito, a sua função é evidenciar o valor de mercado do patrimônio líquido. Mantém estreita relação com o balanço especial previsto no artigo 1.031 do CC de 2002. Porém não pode ser confundido com este, uma vez que o balanço especial reporta a situação patrimonial da entidade na data do evento, já no primeiro os ativos a valor de mercado, passivos a valor presente e o goodwill, quando a sociedade tem capacidade para tê-lo (Caríssimo 2014).

As demonstrações contábeis usuais de empresas em processo de avaliação judicial estão registradas valores de entrada. Logo, exige-se que sejam reelaboradas à luz das determinações judiciais (Ornelas 2000).

$\mathrm{Na}$ elaboração do balanço de determinação são executados alguns ajustes extras contábeis, de modo que os elementos patrimoniais reflitam os respectivos valores líquidos de realização na data do evento. Esses ajustes visam diminuir a diferença entre aquilo que está registrado na contabilidade e o real valor econômico do negócio, uma vez que a contabilidade tradicional não reflete o real valor da empresa objeto da avaliação.

E apesar de serem realizados esses ajustes Hoog (2010) destaca que a estrutura deve se manter semelhante à de um balanço patrimonial tradicional, afim de evidenciar os ativos, passivos e patrimônio líquido. E vai além, descrevendo que o mesmo pode ser reconhecido, mas não confundido, como um balanço especial, cujo objetivo é determinar haveres do sócio retirante ou morto, acompanhado com notas explicativas para uma melhor transparência.

Embora não existam lei ou norma instituindo ou obrigando a utilização do balanço de determinação para apuração de haveres, Ornelas (2000) e Hoog (2010), consideram a sua utilização como procedimento contábil que visa suprir informações mais precisas e confiáveis 
quando da resolução societária, cumprindo de forma eficaz o entendimento emanado do Poder Judiciário.

Até o ano de 2010, a Norma Brasileira de Contabilidade (NBC) T - 4 (Resolução no 732/92) emanada do Conselho Federal de Contabilidade (CFC), abordava sobre a avaliação patrimonial e determinava os parâmetros para elaboração do balanço de determinação. Em razão da convergência das Normas Brasileiras de Contabilidade aos padrões internacionais iniciada em 2008 e concluída em 2010, a NBC T - 4 foi revogada pela Resolução $n^{\circ} 1.283 / 10$ também emitida pelo CFC. Apesar da norma revogada não ter uma correspondente específica, o seu conteúdo foi abrangido pelas normas convergidas durante o processo de convergência.

Caríssimo (2014), destaca que mesmo não estando explícito na norma revogatória da NBC T - 4, pode-se concluir que essa revogação foi feita em virtude da incorporação do valor justo, do teste de impairment, dentre outras normatizações afinadas com os novos padrões International Financial Reporting Standards (IFRS).

Ornelas (2000, p. 135), apresenta como deverá ser composto e apresentado o balanço de determinação:

Tabela 1

\section{Estrutura do balanço de determinação}

\section{ATIVO}

\section{Disponibilidades}

- Caixa e bancos (conforme saldos ajustados)

- Aplicações de liquidez imediata (valor aplicado mais rendimentos)

- Aplicações em ouro (valor de mercado menos despesas de corretagem)

\section{Créditos}

- Valores e títulos a receber a curto e longo prazo (valor de face trazido a valor presente, acrescido, se for o caso, da renda financeira contratada)

- Despesas antecipadas (pelo valor a apropriar, após a data do evento)

- Adiantamentos a fornecedores (reconhecer eventual ganho monetário)

\section{Estoques}

- Estoques vendáveis (preço de venda a vista, deduzido das despesas e da margem de lucro - se mercado organizado - para mercadorias, produtos acabados; produtos semielaborados e serviços em andamento: por preços à vista equivalentes ao estado de acabamento; matérias-primas e materiais e componentes: preço a vista de aquisição)

- Estoque de imóveis para venda (valor de realização, deduzido de despesas de corretagem)

- Estoques obsoletos (valor provável de liquidação)

Investimentos

- Ações de companhias abertas (cotação de Bolsa de Valores)

- Empresas controladas e coligadas (valor do patrimônio líquido a valores de mercado das sociedades controladas ou coligadas)
PASSIVO
Obrigações
- Fornecedores de bens e serviços (valor de face trazido a valor presente)
- Adiantamento de clientes (reconhecer eventual perda monetária)
- Trabalhistas correntes (pelo valor original, com encargos até a data)
- Provisões trabalhistas correntes (valor original, com encargos até a data)
- Financiamentos (principal e encargos até a data)
- Outras contas a pagar (valor original e/ou valor presente)

\section{Provisões}
- Provisões tributárias: ganho de capital (cálculo pericial contábil)
- Contingências trabalhistas, tributárias, comerciais (cálculo pericial contábil) 


\section{APURAÇÃO DE HAVERES E AS DIFICULDADES DO PERITO CONTADOR}

Conclusão

\section{Imobilizado}

- Imóveis (valor do laudo pericial de engenharia menos despesas de corretagem)

- Máquinas e equipamentos (laudo pericial de PATRIMÔNIO LÍQUIDO (VALOR DA SOCIEDADE)

engenharia, se material)

- Móveis, utensílios, ferramentas softwares, equipamentos de informática etc. (valor de mercado; considerada a sua materialidade: valor líquido contábil)

- Veículos e direito de uso de linhas telefônicas (valor de mercado)

Diferido

- Despesas pré-operacionais, despesas com pesquisa e desenvolvimento de produtos (valor econômico provável)

\section{Ativo intangível}

- Marcas, patentes, ponto comercial, concessões etc. (cálculo perícia contábil)

- Goodwill (cálculo pericial contábil do sobrevalor)

Nota. Adaptado de “Avaliação de Sociedade" de Ornelas, 2000, p. 135.

\subsubsection{Características do Balanço de Determinação}

Com o objetivo de atribuir o real valor da empresa objeto da avaliação, na apuração de haveres é necessário atribuir valor para todos os elementos patrimoniais, sejam eles monetários ou não monetários. O Comitê de Pronunciamentos Contábeis por meio do Pronunciamento Técnico 02 (R2) define os itens monetários como unidades de moeda mantidas em caixa e ativos e passivos a serem recebidos ou pagos em um número fixo ou determinado de unidades de moeda, enquanto os não monetários, não tiveram uma definição na última revisão desse pronunciamento técnico, porém, definiu a sua característica essencial, que compreende a ausência do direito a receber (ou da obrigação de entregar) um número fixo ou determinável de unidades de moeda.

A seguir, de acordo com Perez e Famá (2004, p. 108 - 109), os principais ajustes e pontos de atenção aos elementos patrimoniais para elaboração do balanço de determinação. Eles são necessários para refletir o valor da empresa o mais próximo possível do real, evitando assim distorções. 
Tabela 2

Ajustes aos elementos patrimoniais

Avaliação dos Itens Monetários:

Disponibilidades:

a) Saldos em caixa e contas correntes: correspondem ao seu próprio valor;

b) Moeda estrangeira: convertida pela taxa de câmbio (venda) correspondente, na data base; c) Aplicações financeiras: somatória do valor originalmente aplicado e dos rendimentos líquidos proporcionais até a data base; d) Outros ativos financeiros: valor de mercado na data base, menos despesas de realização.

Créditos: Direitos e títulos de crédito serão avaliados a valor presente na data base, considerando os ajustes de atualização monetária, variação cambial e outros contratuais, excluindo-se os créditos já vencidos.

Obrigações: São calculadas a valor presente na data base, acrescidas dos encargos de inadimplência, se devidos.

Provisões: São examinadas as existentes e realizados os ajustes técnicos necessários para que os valores estejam refletidos com propriedade na data base.

\section{Avaliação dos Itens Não Monetários:}

Estoques: São sempre avaliados a valor de mercado, ou seja, pelo preço à vista ou seu equivalente na data base, deduzido das despesas de realização, não sendo considerados os estoques obsoletos ou invendáveis.

\section{Investimentos Permanentes:}

Participações em empresas controladas ou coligadas são avaliadas pelo valor de mercado do patrimônio líquido na data base, apurado também conforme Balanço de Determinação e transferidos via equivalência patrimonial.

Imobilizado: São também avaliados a preços de mercado, deduzidos das despesas de realização. Muitas vezes a avaliação de alguns itens que compõe o ativo imobilizado requer a realização de outras perícias técnicas e de engenharia.

Ativo Diferido: São avaliados com base no custo de aplicação ou investimento, deduzidos das respectivas amortizações até a data base.

Contingências: Todas as contingências ativas e passivas conhecidas, originárias de todos os campos jurídicos devem ser consideradas, avaliadas por advogados e consignadas no Balanço de Determinação, através de ajustes no patrimônio líquido.

Nota. Adaptado de "Métodos de avaliação de empresas e o balanço de determinação" de Perez e Famá, 2004, Revista Administração em Diálogo, v. 6, n. 1, p. 108-109.

Como já mencionado, até o ano de 2010 a NBC T-4 dava as diretrizes para elaboração do balanço de determinação. Com a harmonização e convergências das regras contábeis brasileiras aos padrões internacionais, dois critérios avaliatórios de ativos e passivos devem nortear a elaboração do balanço de determinação: "valor justo" (valor de mercado) e "valor presente".

O Comitê de Pronunciamentos Contábeis define valor justo “... como o preço que seria recebido pela venda de um ativo ou que seria pago pela transferência de um passivo em uma transação não forçada entre participantes do mercado na data de mensuração" (Pronunciamento Técnico CPC 46, 2012, item 9). Enquanto o Pronunciamento Técnico 12 do mesmo Comitê define valor presente como "a estimativa do valor corrente de um fluxo de caixa futuro, no curso normal das operações da entidade".

Tendo em vista esses dois critérios avaliatórios, para que o balanço de determinação demonstre o real valor da entidade objeto da avaliação, faz-se necessário registrar a valor presente os direitos e obrigações, bem como o valor justo de ativos e passivos.

Uma outra característica a ser observada quando na elaboração do balanço de determinação é o aspecto temporal. Há uma diferença de tempo considerável entre a data da dissolução parcial da sociedade - que é a data base para apuração do valor da empresa, e aquela 


\section{APURAÇÃO DE HAVERES E AS DIFICULDADES DO PERITO CONTADOR}

que o perito contador produz o laudo de avaliação. O que era futuro na data da dissolução parcial da sociedade, tornou-se passado no período que o laudo foi finalizado. Provisões e/ou perdas estimadas na data da dissolução parcial da sociedade podem ser comparadas com os valores ocorridos. Ao passo que verificações físicas disponíveis à época, como por exemplo, inventários dos estoques e contagem de valores existente no caixa, são impossíveis de fazer (Paulo et al., 2006).

Após os ajustes avaliatórios nos elementos patrimoniais obtém-se o valor do patrimônio líquido a valores de mercado. Cumprida a etapa da elaboração do balanço de determinação, a próxima fase é calcular o goodwill - mais uma característica a ser observada na confecção do balanço de determinação.

Caríssimo (2014), define goodwill como a diferença entre o valor econômico de uma sociedade e o valor total de seus ativos avaliados a valor de mercado, ou seja, é a mais valia da sociedade. Perez e Famá (2004), nos ensina que ele é o descompasso existente entre o valor econômico da sociedade e seu valor patrimonial. Ainda, de acordo com Perez e Famá (2004, p.110), goodwill "não está refletido no balanço patrimonial, não sendo depreciável ou amortizável, pertence a empresa como um todo, não existindo separadamente".

\section{MÉTODO DA PESQUISA}

Esta pesquisa quanto aos seus objetivos apresenta-se como descritiva, conforme Gil (2010) a pesquisa descritiva tem por objetivo descrever as características de uma população, de um fenômeno ou de uma experiência.

A natureza deste artigo é qualitativa porque qualifica as principais dificuldades encontradas pelo perito contador na apuração de haveres em processos judiciais.

Conforme Gibbs (2009) os pesquisadores qualitativos estão interessados em ter acesso a experiências, interações e documentos em seu contexto natural, e de uma forma que dê espaço às suas particularidades e aos materiais nos quais são estudados.

Quanto aos procedimentos de pesquisa trata-se de uma pesquisa de campo com aplicação de questionário, que de acordo com Marconi e Lakatos (2010) questionário é um instrumento de coleta de dados, constituído por uma série ordenada de perguntas, que devem ser respondidas por escrito e sem a presença do entrevistador. Em geral, o pesquisador envia o questionário ao informante, pelo correio ou por um portador, depois de preenchido, o pesquisado devolve-o do mesmo modo. Junto com o questionário deve-se enviar uma nota ou carta explicando a natureza da pesquisa, sua importância e a necessidade.

O questionário possui 13 questões sobre as principais dificuldades do perito contador na apuração de haveres em processos judiciais na cidade de São Paulo. A aplicação do questionário somente para aqueles com atuação na cidade de São Paulo, foi pelo fato das varas cíveis judiciais da cidade concentrar boa parte dos processos de dissolução de sociedade discutidos no judiciário brasileiro, logo, os profissionais com atuação nessas varas possuem mais experiência com o objeto da pesquisa. O questionário foi enviado por e-mail para os peritos contadores associados à Associação dos Peritos Judiciais do Estado de São Paulo (APEJESP) e para aqueles do Cadastro Nacional de Peritos Contábeis (CNPC). Ressalta-se que não foi remetido $e$-mail para todos os profissionais da APEJESP e nem para todos do CNPC.

Para elaborar as questões definiu-se como premissas os principais obstáculos presentes nas apurações de haveres em processos judiciais, depoimentos de profissionais com vasta experiência em apuração de haveres sob o comando do judiciário, situações que dificultam o desenvolvimento dos trabalhos e os apontamentos da literatura sobre os principais fatores que influenciam a apuração de haveres em uma dissolução societária.

O questionário foi encaminhado para 45 peritos contadores no período de 06/11/2019 a 11/11/2019. No quarto dia de aplicação houve uma grande redução no recebimento de 
questionários respondidos e por isso a abrangência de aplicação foi de apenas 6 dias. Ao todo, foram recebidos 24 questionários respondidos, portanto, considerados válidos para fazer as análises, quantificação e qualificação.

\section{ANÁLISE DOS RESULTADOS}

No início do questionário preocupou-se em realizar uma identificação das características dos respondentes. Com as respostas obtidas percebe-se que além da formação acadêmica em Ciências Contábeis os respondentes obtiveram outra formação acadêmica, variando entre Administração, Economia e Direito. Ficou evidenciando conforme tabela 3 que grande parte deles têm especialização na área de perícia, que é algo positivo, pois estão qualificados para atender as demandas da atividade pericial.

Tabela 3

\section{Especialização}

\begin{tabular}{c|ccc}
\hline \multicolumn{1}{c}{ Sim } & Não & Total \\
\hline $\begin{array}{c}\text { Especialização na área } \\
\text { de Perícia }\end{array}$ & $66,7 \%$ & $33,3 \%$ & $100,0 \%$ \\
\hline
\end{tabular}

Nota. Elaborado pelos autores

Quando perguntado sobre o tempo de atuação, 66,7\% dos peritos responderam que atuam há mais de 16 anos, como se verifica na tabela 4 . Analisando os resultados sobre o tempo de atuação juntamente com os da busca por qualificação, observa-se que mesmo tendo uma vasta experiência, os respondentes não deixaram de buscar por qualificação, atendendo assim a necessidade de busca por conhecimento exigido do perito contador.

Tabela 4

Tempo de atuação

\begin{tabular}{ccc}
\hline Tempo de atuação & Respondentes & Percentual \\
\hline 0 a 5 anos & 4 & $16,7 \%$ \\
6 a 10 anos & 2 & $8,3 \%$ \\
11 a 15 anos & 2 & $8,3 \%$ \\
16 a 20 anos & 3 & $12,5 \%$ \\
Mais de 20 anos & 13 & $54,2 \%$ \\
\hline Total & $\mathbf{2 4}$ & $\mathbf{1 0 0 \%}$ \\
\hline
\end{tabular}

Nota. Elaborado pelos autores.

Ao ser questionado sobre a quantidade de avaliações de sociedades em processos judiais, 62,5\% dos respondentes disseram ter avaliado mais de 10 empresas. Desses que afirmaram ter valorado mais de 10 entidades, 41,7\% fizeram mais de 20 avaliações. Esses resultados confirmam a vasta experiência dos entrevistados apontada anteriormente.

Após a identificação dos respondentes no início do questionário, passou-se a tratar sobre as principais dificuldades do perito contador nas apurações dos haveres em processos judiciais.

Foi perguntado sobre o grau de dificuldade dos respondentes quando presentes algumas situações na apuração de haveres, tais como: a) Ausência do balanço especial; b) Ausência do inventário dos estoques; c) Inexistência de documentos que suportam os fatos contábeis; e d) Escrituração contábil deficitária. Como demonstrado na tabela 5, ao se depararem com tais circunstâncias, o grau de dificuldade para valorar uma empresa é extremamente alto para $33,3 \%$, alto para $41,7 \%$, nem alto nem baixo para $20,8 \%$ e baixo para $4,2 \%$ dos respondentes. 


\section{APURAÇÃO DE HAVERES E AS DIFICULDADES DO PERITO CONTADOR}

Com esses resultados fica evidente a importância da contabilidade em uma apuração dos haveres em processos judiciais.

Tabela 5

Grau de dificuldade diante de certas circunstâncias

\begin{tabular}{ccc}
\hline Grau & Respondentes & Percentual \\
\hline Extremamente alto & 8 & $33,3 \%$ \\
Alto & 10 & $41,7 \%$ \\
Nem alto nem baixo & 5 & $20,8 \%$ \\
Baixo & 1 & $4,2 \%$ \\
Extremamente baixo & 0 & 0 \\
\hline Total & $\mathbf{2 4}$ & $\mathbf{1 0 0 \%}$
\end{tabular}

Nota. Elaborado pelos autores.

A literatura abordada ao longo deste artigo corrobora com esses resultados. Paulo et al. (2006), apontam como problema nas apurações de haveres em processos judiciais a inexistência ou baixo nível de confiabilidade na escrita contábil. Ornelas (2003), classifica como desafios a ausência de balanço especial e a inexistência de escrituração contábil regular nas avaliações de participações societárias.

Quando perguntado se a ausência da escrituração contábil contribui para uma distorção dos resultados nas apurações de haveres em processos judiciais e se na opinião deles é mais difícil valorar uma empresa quando não há o balanço especial, todos responderam que inexistindo a escrituração contábil é certo a distorção nos resultados, já na ausência do balanço especial, 79,20\% responderam que é mais difícil valorar uma empresa quando ele não existe.

Tais resultados confirmam o que dizem. Mondandon et al. (2008) que diversos fatores têm influência na valoração de sociedades em processos judiciais, um desses fatores é a não devida importância à contabilidade. Assim, pode-se chegar à conclusão de que a escrituração contábil é indispensável para uma justa apuração de haveres em processos judiciais.

Um outro aspecto apontado na pesquisa é a omissão de dados e/ou informações pelas partes envolvidas no litígio. Todos os respondentes afirmaram que se houver omissão de dados e/ou informações, a correta apuração de haveres em processos judiciais pode ser prejudicada.

Essa unanimidade não vai contra a literatura. Mondandon et al. (2008) nos ensina também que a omissão de dados e/ou informações valiosos é um fator que pode influenciar na avaliação de sociedades em processos judiciais.

Os respondentes também foram questionados sobre o grau de dificuldade para fazer a avaliação especificamente de três elementos patrimoniais: estoque, intangível e goodwill.

Sobre o grau de dificuldade para valorar o estoque, os resultados foram os seguintes: extremamente alto para $8,3 \%$, alto para $41,7 \%$, nem alto nem baixo para $33,3 \%$, baixo para $12,5 \%$ e extremamente baixo para $4,2 \%$, como se verifica na tabela 6 . 
Tabela 6

Grau de dificuldade para valorar o estoque

\begin{tabular}{ccc}
\hline Grau & Respondentes & Percentual \\
\hline Extremamente alto & 2 & $8,3 \%$ \\
Alto & 10 & $41,7 \%$ \\
Nem alto nem baixo & 8 & $33,3 \%$ \\
Baixo & 3 & $12,5 \%$ \\
Extremamente baixo & 1 & $4,2 \%$ \\
\hline Total & $\mathbf{2 4}$ & $\mathbf{1 0 0 , 0 \%}$ \\
\hline
\end{tabular}

Nota. Elaborado pelos autores.

Paulo et al. (2006) afirmam que em decorrência de um tempo considerável entre a data da dissolução societária e a data que o perito contador foi nomeado para elabora o laudo de avaliação, verificações físicas disponíveis à época, como por exemplo a do estoque, são impossíveis de realizar. É possível que essa dificuldade para avaliar o estoque seja a existência do intervalo de tempo entre essas duas datas.

Para o intangível os resultados foram os seguintes: extremamente alto para $16,7 \%$, alto para $41,7 \%$, nem alto nem baixo para $33,3 \%$ e baixo para $8,3 \%$, como se verifica na tabela 7 .

Tabela 7

Grau de dificuldade para valorar o intangível

\begin{tabular}{ccc}
\hline Grau & Respondentes & Percentual \\
\hline Extremamente alto & 4 & $16,7 \%$ \\
Alto & 10 & $41,7 \%$ \\
Nem alto nem baixo & 8 & $33,3 \%$ \\
Baixo & 2 & $8,3 \%$ \\
Extremamente baixo & 0 & $0,0 \%$ \\
\hline Total & $\mathbf{2 4}$ & $\mathbf{1 0 0 \%}$
\end{tabular}

Nota. Elaborado pelos autores.

De acordo com os dados apresentados, 58,4\% dos respondentes têm dificuldade para valorar o intangível, tal dificuldade pode ser atribuída ao fato do intangível ser um dos elementos patrimoniais mais difícil de avaliar. Segundo Hendricksen e Breda (1999) os ativos intangíveis compõem uma das áreas mais complexas da contabilidade, parte em razão das dificuldades de definição, mas principalmente pelas incertezas acerca da mensuração de seus valores.

Sobre o grau de dificuldade para valorar o goodwill, os resultados foram diferentes daqueles encontrados para o estoque e intangível. Foi extremamente alto para 12,5\%, alto para $29,2 \%$, nem alto nem baixo para $45,8 \%$, baixo para $8,3 \%$ e extremamente baixo para $4,2 \%$, conforme demonstrado na tabela 8. Aqui cabe atenção para a neutralidade, maior parte com $45,8 \%$ e para aqueles que afirmaram encontrar dificuldade para valor o goodwill, com 41,7\%.

Com esses resultados pode-se extrair duas análises:

I) Sobre a neutralidade é possível que isso ocorra pelo fato de nem sempre ser necessário apurar o goodwill, uma vez que na maioria das apurações de haveres para fins judiciais, a literatura deste artigo nos ensina que envolve empresas de pequeno porte e, poucas a vezes, essas empresas apresentam atributos para ter o goodwill;

II) Uma outra análise que pode ser realizada é sobre aqueles que afirmaram encontrar dificuldade para valor o goodwill, essa dificuldade pode estar associada a subjetividade envolvida na avaliação de sociedades. 


\section{APURAÇÃO DE HAVERES E AS DIFICULDADES DO PERITO CONTADOR}

Tabela 8

Grau de dificuldade para valorar o goodwill

\begin{tabular}{ccc}
\hline Grau & Respondentes & Percentual \\
\hline Extremamente alto & 3 & $12,5 \%$ \\
Alto & 7 & $29,2 \%$ \\
Nem alto nem baixo & 11 & $45,8 \%$ \\
Baixo & 2 & $8,3 \%$ \\
Extremamente baixo & 1 & $4,2 \%$ \\
\hline Total & $\mathbf{2 4}$ & $\mathbf{1 0 0 \%}$ \\
\hline
\end{tabular}

Fonte: Elaborado pelos autores.

$\mathrm{Na}$ última questão foi solicitado aos respondentes a opinião deles sobre algo comum presente nas apurações de haveres em processos judiciais e que dificulta a valoração da entidade. As respostas citadas mais vezes foram: a) escrituração contábil deficitária ou inexistente, b) ausência de documentação probante e c) falta de informações fidedignas.

Mais uma vez os resultados obtidos estão em harmonia com a literatura que trata do tema. Ornelas (2003), Paulo et al. (2006) e Mondandon et al. (2008) nos ensinam que essas respostas mais citadas são vistas nas apurações de haveres em processos judiciais como situações que dificultam a avaliação da empresa para fins judiciais, bem como, desafios para os peritos contadores.

Com os resultados obtidos na pesquisa, percebe-se que nas apurações de haveres em processos judiciais, o perito contador se depara com uma série de situações que dificultam o desenvolvimento do seu trabalho, tendo como consequência interferência nos resultados da valoração.

\section{CONCLUSÕES}

Analisando os resultados obtidos observa-se que nas apurações de haveres em processos judiciais, os peritos contadores deparam com situações que, dependendo do seu grau de relevância, podem alterar o resultado de uma avaliação societária. Geralmente isso ocorre nas valorações de microempresas e nas empresas de pequeno porte, uma vez que as empresas enquadradas nesses grupos tendem a não apresentar uma contabilidade estruturada e efetiva ou então não possuem uma boa gestão.

Dependendo do seu grau de relevância, as circunstâncias que podem alterar o resultado de uma avaliação empresarial comandada pelo judiciário são: a) ausência de escrituração contábil ou deficitária, b) falta de documentação que dão suporte aos fatos contábeis, c) falta do balanço especial à época da resolução societária e, d) omissão de dados e/ou informações pelas partes envolvidas no litígio.

Ao longo deste artigo discutiu-se as principais dificuldades encontradas pelo perito contador na apuração de haveres em dissolução societária comandada pelo judiciário.

Dentre as dificuldades, a valoração especificamente de dois elementos patrimoniais ganhou destaque: estoque e intangível. De acordo com os resultados da pesquisa, os respondentes afirmaram encontrar dificuldade para atribuir valor a esses dois elementos patrimoniais. Para o estoque essa dificuldade pode estar associada a decorrência considerável de tempo entre a data da resolução societária e aquela da produção do laudo de avaliação, tornando impossível fazer o levantamento físico, enquanto para o intangível pelo fato de ser uma das áreas mais complexa da contabilidade em razão da incerteza em relação a mensuração de seus valores.

Um outro elemento patrimonial que também cabe destacar é o goodwill. Para boa parte 
dos entrevistados o grau de dificuldade para valorar o goodwill não é alto e nem baixo, enquanto para uma parcela significativa é alto ou extremamente alto. Para esses que afirmaram encontrar dificuldade para a valorização, é possível que tal dificuldade existe pelo fato da subjetividade presente nas avaliações de sociedades.

As dificuldades não se restringiram apenas na valoração do intangível, estoque e goodwill. Ficou evidente também na pesquisa que dentre as dificuldades do perito contador está a de valorar os elementos patrimoniais, quando presente na apuração de haveres circunstâncias que dificultam o desenvolvimento do seu trabalho, tais como: falta de escrituração contábil ou deficitária, ausência de documentação que dão suporte aos fatos contábeis, falta do balanço especial à época da resolução societária e omissão de dados e/ou informações pelas partes envolvidas no litígio.

Como limitação da pesquisa destaca-se o fato de a população estar localizada geograficamente na cidade de São Paulo, limitando assim a generalização dos resultados obtidos.

As constatações do presente estudo não esgota o assunto. Ao trazer para discussão as principais dificuldades do perito contador nas apurações de haveres em processos judiciais, sugere-se para pesquisas futuras um estudo sobre quais as dificuldades do perito contador em valorar especificamente o intangível, pois trata-se de um elemento patrimonial que envolve muita subjetividade e complexidade na mensuração do seu valor

\section{REFERÊNCIAS}

Caríssimo, C. R. (2014). Análise da preferência dos peritos contadores quanto à escolha do método de avaliação de sociedades em perícias de apuração de haveres com base na Análise Hierárquica (AHP) (Dissertação de Mestrado). Universidade Federal de Minas Gerais - UFMG, Minas Gerais, MG, Brasil. Recuperado de https://repositorio.ufmg.br/bitstream/1843/BUOS-

9NNHPA/1/claudio_car_ssimo_31_07_14.pdf

Damodaran, A. (1997). Avaliação de investimentos: ferramentas e técnicas para determinação do valor de qualquer ativo. Rio de Janeiro: Qualitymark.

Fonseca, P. M. Correa da (2012). Dissolução parcial, retirada e exclusão de sócio. São Paulo: Atlas.

Gibbs, G. (2009). Análise de dados qualitativos, Porto Alegre: Artmed.

Gil, A. C. (2010). Como elaborar projetos de pesquisa. (5a ed.). São Paulo: Atlas.

Hendricksen, E. S.; Breda, M. F. V. (1999). Teoria da contabilidade. (5a ed.). São Paulo: Atlas.

Hoog, W. A. Z. (2010). Resolução de sociedade e Avaliação do Patrimônio na Apuração de haveres (4a ed.). Curitiba: Juruá.

Lakatos, E. M., Marconi, M. A. (2010). Fundamentos de metodologia científica. São Paulo: Atlas.

Lei n. 10.406, de 10 de janeiro de 2002. Institui o Código Civil. Recuperado de <http://www.planalto.gov.br/ccivil_03/leis/2002/110406.htm>.

Lei n. 13.105, de 16 de março de 2015. Altera e revoga dispositivos da Lei 5.869, de 11 de 


\section{APURAÇÃO DE HAVERES E AS DIFICULDADES DO PERITO CONTADOR}

janeiro de 1973. Recuperado de http://www.planalto.gov.br/ccivil_03/_ato20152018/2015/lei/113105.htm.

Martins, E. (2001). Avaliação de empresas: da mensuração contábil à econômica. São Paulo: Atlas.

Mondandon, M. M., Siqueira, J. R. M. D., \& Ohayon, P. (2008). Avaliação de empresas em perícias contábeis: um estudo de casos. Pensar Contábil, 10(39).

Ornelas, M. M. D. (2003). Avaliação de sociedade (2a ed.). São Paulo: Atlas.

Ornelas, M. M. D. (2000). Contribuição à formulação de um sistema conceitual contábil de apuração de haveres em processos judiciais (Tese de Doutorado). Universidade de São Paulo - USP. São Paulo, SP, Brasil.

Paulo, E., da Cunha, J. V. A., de Alencar, R. C., \& Martins, E. (2006). As práticas dos peritos contadores na apuração de haveres. Revista Brasileira de Gestão de Negócios-RBGN, 8(22), 23-36.

Perez, M. M., \& Famá, R. (2004). Métodos de avaliação de empresas e o balanço de determinação. Revista Administração em Diálogo-RAD, 6(1).

Pronunciamento técnico CPC 02 (R2), de 07 de outubro de 2010. Efeitos das mudanças nas taxas de câmbio e conversão de demonstrações contábeis. Recuperado de http://static.cpc.aatb.com.br/Documentos/62_CPC_02_R2_rev\%2013.pdf

Pronunciamento técnico CPC 46, de 20 de dezembro de 2012. Mensuração do valor justo. Recuperado de http://static.cpc.aatb.com.br/Documentos/395_CPC_46_rev\%2014.pdf

Pronunciamento técnico CPC 12, de 17 de dezembro de 2008. Ajuste a valor presente. Recuperado de http://static.cpc.aatb.com.br/Documentos/219_CPC_12.pdf 